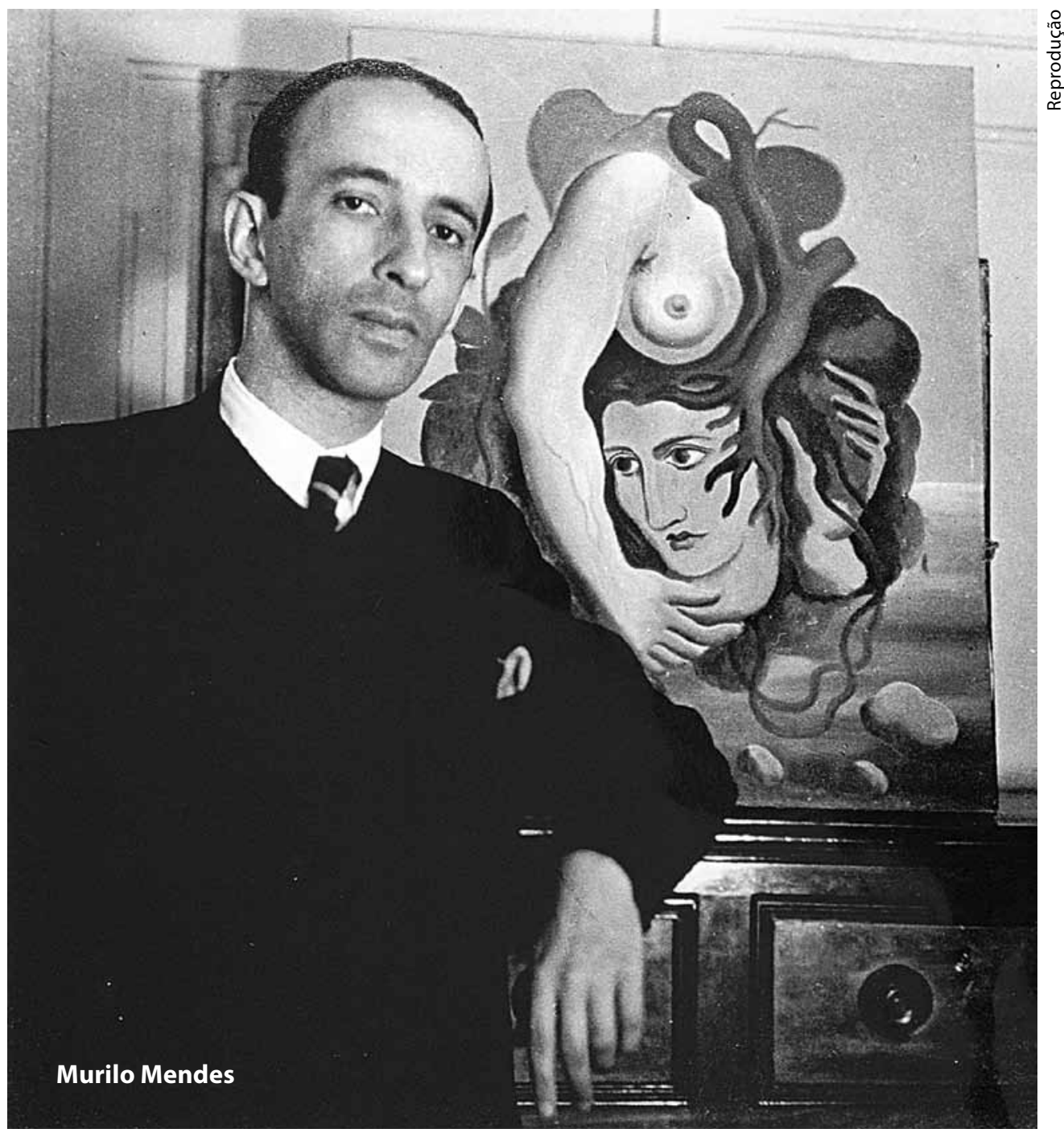

\title{
RETRATOS-RELÂMPAGO: DESPEDIDA E COMEMORAÇÃO
}

Maria Betânia Amoroso 


\section{MARIA BETÂNIA \\ AMOROSO \\ é professora do \\ Departamento \\ de Teoria Literária \\ da Unicamp, autora \\ de Pier Paolo Pasolini \\ (Cosac Naify).}

Agradeço a Samuel Titan Jr. a sugestão do título.

1 La Fiera Letteraria foi um importante veículo de divulgação de autores, obras e assuntos ligadosà literatura eàs artes. Criada em 1925 em Milão, a revista foi transferida para Roma em 1929. Deixa de circular em 1936, retornando dez anos depois, tendo Gianfranco Contini e Giuseppe Ungaretti, entre outros, no seu ConselhoEditorial.Em 1977 sai de cena.

2 Expressão, com pequenas variações, insistentemente usada pela imprensa italiana e por comentadores emgeral paradesignar Murilo Mendes.

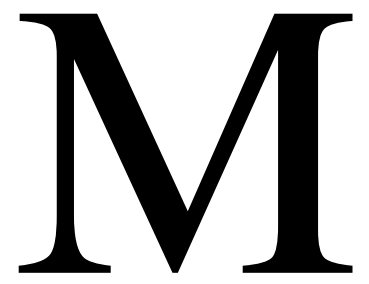

urilo Mendes morou por dezoito anos em Roma, de 1957 a 1975 , quando morreu, em Lisboa, no verão. Anteriormente, de 1952 a 1956, viajara pela Europa: esteve na Bélgica e na Holanda; fez, em 1953, conferência sobre Jorge de Lima na Sorbonne.

Estrangeiro importante, prova-o o fato de que em 1963 uma revista cultural renomada, sabendo de sua presença em Roma, para dar destaque tanto à cidade como ao poeta estrangeiro, convoca-o para falar dela; e ele responde mostrando-a como desdobramento de sua poética. Murilo escreve sobre Roma, respondendo à pergunta "Por que vive em Roma?", formulada pela revista La Fiera Letteraria ${ }^{1}$.

"Vivo em Roma porque aqui posso exercer meu trabalho de professor, escritor e membro de uma sociedade secreta que se propõe dinamitar o monumento de Piazza Venezia. Porque Roma, segundo um célebre soneto de Quevedo, não está mais em Roma, portanto não me sinto mais obrigado a seguir os rastros dos Césares. Porque seu povo é humano e simpático. Porque Roma tem belas mulheres, praças estupendas; este ocre de suas casas me serve de tônico. Porque aqui encontrei amigos deliciosos: que geralmente não creem que $2+2=4$. Porque em Roma existe o Museu de Valle Giulia: quando entro ali me transformo num etrusco. Porque raramente se topam rinocerontes nos seus parques. Pois que é a cidade que vive sob o signo do juízo universal e da mais formidável história em quadrinhos, exatamente o juízo universal de Miguel Ângelo, o 'Arrabbiato' por excelência. Porque vivendo em Roma não sinto necessidade de ir à lua. Somos aqui, todos, lunáticos. Porque em Roma posso ver João 23, isto é, a excomunhão da bomba, o progresso do ecumenismo e da paz" (Mendes, 2001b, pp. 148-9).

Desde o primeiro momento, ao fixar residência no país, ao lançar um livro novo ou então ao receber alguma homenagem - como o Prêmio Etna-Taormina, em 1972 -, o poeta mineiro é apresentado, entrevistado, comentado, resenhado por jornais e revistas.

Contudo, se inicialmente a leitura desses artigos, textos, ensaios, escritos por italianos prometia indicar linhas, desenhos críticos que franqueariam a leitura da obra muriliana por parte de seus leitores italianos, o que se encontrou foi a lenta construção de uma imagem pública do poeta estrangeiro, sintetizada pela expressão "o poeta brasileiro de Roma" 2 .

Jornais e revistas, mais ou menos especializados em literatura, elegem como objetos culturais o que gravita ao redor da obra e da personalidade do poeta - inserindo-o, portanto, direta ou indiretamente, dentro de uma rede de lugares e sentidos, a constelação do escritor estrangeiro, que se articulam a partir dessa figura. Ressalte-se, porém, que tal desvio de rota - da leitura crítica da obra em si para a observação sobre a figuração do poeta - se impôs durante a leitura dos jornais e revistas que focalizaram em suas páginas o poeta brasileiro. A situação é nova: o poeta internacional e mundano, ao se transferir para a Itália, passará a ser lido e comentado a partir de princípios e critérios distintos daqueles da crítica brasileira que o acompanhava desde os anos 30. Tal situação obrigatoriamente leva à desnaturalização do olhar crítico brasileiro - se é que assim é possível falar. O que foi preciso mobilizar para pôr em contato dois continentes não só culturalmente diversos, mas de de tradições extremamente desiguais? O que os textos indicam é que para os críticos italianos ler a poesia muriliana foi um exercício que implicou a definição de algumas salvaguardas, retiradas ora da biografia, ora das poucas noções que circulavam sobre a poesia brasileira, das escassas obras de referência crítica, ou mesmo de traduções, mas que principalmente advinham das relações que o poeta estabeleceu com a cidade, isto é, a leitura se dá pela intermediação e pela localização do poeta entre dois campos literários, o italiano e o brasileiro. Há um evidente esforço, tanto da parte de Murilo como dos que o leem, 
no sentido de tornar familiar o que é estrangeiro. O que esses leitores buscam é algum motivo que sirva de apoio para o enfrentamento de obra tão pessoal, que não se entrega com facilidade, nem mesmo para os leitores que pertencem à mesma tradição. Contudo, $\mathrm{o}$ fenômeno que se constata é menos atribuível ao indivíduo do que às próprias características do confronto entre culturas estáveis e culturas instáveis ${ }^{3}$.

Seguindo, ano após ano, o que foi escrito sobre Murilo pelos italianos, algumas constatações foram aos poucos se impondo: ao mesmo tempo em que os leitores brasileiros iam perdendo de vista o que o poeta apresentava como produção literária, culminando esse processo de distanciamento nos textos compostos em língua italiana, Murilo Mendes ia ganhando reconhecimento como poeta e personalidade intelectual no meio cultural italiano ${ }^{4}$. Mas havia o desconhecimento quase absoluto da poesia feita no Brasil, sem falar do desconhecimento do próprio país e de sua cultura; havia a diferença de forças entre as duas culturas envolvidas, que sempre eximiu o europeu de conhecer o que é de fora: tudo se apresentando como um enorme empecilho para quem se aventurava a escrever sobre o poeta.

Por outro lado, o próprio poeta também se vê preso à circunstância. Conhecedor, como poucos brasileiros da época, do mundo literário, dos nomes importantes, das obras da cultura europeia do final do século XIX e da primeira metade do século XX, Murilo irá, consciente ou inconscientemente, ajudar a definir sua persona literária, fornecendo para os jornalistas, críticos ou colegas da universidade que se dispunham a escrever sobre ele um quadro de referências que, por sua vez, fornecia os instrumentos para ler sua poesia.

É certo, porém, que Murilo Mendes foi procurado pela imprensa, que alguns nomes de prestígio e importância intelectual escreveram, mais de uma vez, sobre seus livros. O que cabe conhecer são os termos dessa inserção e, em seguida, os modos como foram lidas sua prosa e sua poesia pelos leitores italianos, jornalistas e críticos.
Há, portanto, uma perspectiva dupla a ser considerada: a da crítica brasileira - que continua, depois da transferência de Murilo para a Itália, a lê-lo e interpretá-lo a partir de parâmetros definidos pela fortuna crítica acumulada desde os primeiros anos da década de 1930, mas que pouco acompanhou o desenvolvimento de sua poética na Europa -e a da italiana, que, desconhecendo essa poesia - e também a literatura brasileira em geral busca, por um lado, recursos interpretativos em tradições literárias diversas, como a hispânica e ibérica, e, por outro, cria o mito, que tudo permeia, do poeta brasileiro de Roma ${ }^{5}$.

Acompanhar alguns momentos da transformação da poética muriliana é o que se pretende, em breve, fazer neste ensaio.

Numa entrevista a um jornal italiano, em 16 de junho de 1966, Murilo Mendes anuncia uma mudança:

"Resolvi, apesar da idade, subverter minha linguagem poética e estou escrevendo quatro livros ao mesmo tempo, dois em prosa e dois em poesia. Os de poesia são Contato e Exercícios; os de prosa, Poliedro e Figuras. No último aparecem poetas, artistas em geral, filósofos, em suma, as figuras da minha vida" ${ }^{\text {. }}$

Seis anos depois, por ocasião do recebimento do Prêmio Etna-Taormina, em nova entrevista, confirma seu projeto: "[...] estou escrevendo uma coletânea de retratos de pintores, escritores, poetas com o título Retratos Relâmpago [...]"?.

Ao anunciar que estava escrevendo em prosa, Murilo Mendes atualizava, de algum modo, o público leitor italiano que o tinha como exclusivamente poeta justamente no momento em que um prêmio literário o consagrava. No Brasil, sabíamos que havia prosa já escrita anteriormente, como atesta $O$ Discípulo de Emaús, que tem como data de publicação 1945: a guerra, além de tantas outras incertezas, teria trazido a autorreflexão sobre a oportunidade e o sentido da lírica moderna ${ }^{8}$ ?

A primeira série de retratos, escrita entre 1965 e 1966, última obra publicada em vida
3 Refiro-me aqui ao uso feito por Luiz Costa Lima (1997) das ex pressões. Agradeço a Sérgio Alcides a lembrança do ensaio.

4 Entre os leitores brasileiros mais atentos à produção poética e entre os amigos, a falta de Murilo era lamentada e seu sucesso naEuropa comentado. Tanto nos depoimentos de João Carlos Horta, fotógrafo do filme sobre o poeta Poesia em Pânico, dirigido por Alexandre Eulálio como no de Armando Freitas - que, jovem poeta na época, relembraa passagem de Murilopelo Rio, ondeo encontrou no Paysandu Hotel, no bairro do Flamengo, na década de 70 -, há traços de admiração advinda do valor poético da poesia muriliana, reforçada pela imagem da projeção internacional do mineiro. $(\mathrm{O}$ primeiro depoimento foi dado na Casa de Ruy Barbosa, durante evento que projetou o filme citado, em 6 de dezembro de 2005 No dia 7, Armando Freitas, em conversa lembrou-se da estadia de Murilo no Rio.)

5 Desenvolvi o assunto em Murilo Mendes: $O$ "Poeta Brasileiro" de Roma. V. I: História de uma Leitura (Introdu ção) e V. II: História de umaLeitura(Apêndice), inéditos.

6 Publicado em Momento Sera, 17, giu, 1966.

7 Publicado em La Fiera Letteraria, 19, mar./1972.

8 Luciana Stegagno Picchio destaca Murilo prosador em duas notas. Na primeira escreve: "O Discípulo de Emaús é a obra que representa seu exórdio como autor de prosa (uma prosa poética, aforística, ligada tanto 
ao som quantoao sentido) [...]"; na segunda, acrescentaao sereferir a $A$ Idade do Serrote que, "[...] livro de memórias de um Murilo Mendes 'exilado' na Europa, foi escrito em Roma, nos anos de 1965 e 1966. Saiu em $1^{1}$ edição no Rio em 1968 e revelou ao público brasileiro, que de Murilo Mendes conhecia sobretudo a poesia visionária dos anos 30 e 40, uma nova faceta do Autor. [...] Essencial poeta lírico, mesmo quandoescreve prosa Murilo Mendes tem inspiração breve, um poema, uma página. Nunca escreveria um romance [...]" (in Mendes, 1994, p. 1.692). Embora sejatotalmente compreensível essa interpretação dada à presença da prosa na obra do poeta, não é esse meu interesse. $A$ prosa muriliana que procuro examinar me parece fortemente ligada aos interesses pela crítica de Murilo, interesses esses também presentes nos seus textos sobre artes plásticas, escritos durante toda sua vida e não somente durante a estadia romana, como atesta sua colaboração em jornais brasileiros nas décadas de 1930 e 40 Marta Nehring (2003) estudou o ensaísmo de Murilo no livro Murilo Mendes: Crítico de Arte: a Invenção do Finito; há ainda o estudo de Martinez Leonil (2006) também dedicado a observar a presença da prosa na produção muriliana.

90 início do retrato: "A Piazza del Campidoglio em Roma, singularmente situada numa colina, é um dos postos mais cenográficos da Itália; encerra segundo Aldo Palazzeschi o insondável segredo da Renascen- pelo poeta, em 1973, foi organizada pelo próprio Murilo (Mendes, 1994, p. 1.702)e pode ser lida como uma reflexão sobre a literatura em geral e, em particular, como uma autorreflexão sobre sua própria poética. É isso o que procura apontar, observando as particularidades de sua composição que são caracterizadas pela aproximação da crítica e do ensaísmo, configurados a partir de uma dimensão que é a da memorialística.

Ao organizar o material que deveria constar do livro, Murilo Mendes sentiu a necessidade de acrescentar uma nota, datada de 25 de outubro de 1970, na qual dá explicações sobre algumas "apropriações" ocorridas e sobre a sua falta de unidade. Diz ele:

"Este livro foi escrito em 1965-66. Desde essa época sei que lhe falta unidade estrutural. Se eu dispusesse de tempo, gostaria de ordená-lo diversamente. Caso não possa fazê-lo, poderia ser publicado assim mesmo. O plano original prevê duas séries.

Certos encontros e episódios referem-se a datas anteriores à redação do texto. Baseei-me em apontamentos de cada época.

Em alguns casos, dispensando aspas, inseri no texto palavras de escritores abordados. 'Raimundo Correa', logo se vê, resulta numa colagem.

No capítulo sobre Victor Hugo, a frase de Macedonio Fernández não se refere ao poeta: mas penso que lhe pode ser aplicada com justeza" (Mendes, 1994, p. 1.702).

Na nova poética que Retratos-Relâmpago delineia, portanto, a presença da memória, associada à leitura, tem destaque: serão as impressões deixadas pelos livros lidos ou as anotações a maior contribuição para a feitura dos retratos.

A "falta de unidade" não parece, como afirma o poeta, determinada pela "falta de tempo", mas constitutiva desse novo modo de compor muriliano. Os retratos falam disso.

Marco Aurélio é o retrato que parte da escultura do imperador ao centro da Piazza del Campidoglio - síntese da Roma renascentista nas palavras de Murilo emprestadas do poeta italiano Aldo Palazzeschi ${ }^{9}$. A fonte para a composição vem dos Colloqui con se Stesso ${ }^{10}$, conjunto de reflexões escritas pelo imperador romano, de difícil classificação, compostas fora de qualquer cronologia. Tudo indica que Murilo tenha lido o primeiro dos volumes, uma espécie de testamento interior, no qual Marco Aurélio se lembra das figuras mais importantes de sua vida. A crítica durante muitos anos viu-se incomodada pela falta de unidade da obra, sem que fosse clara a concatenação de tantas reflexões desse imperador melancólico que aceitou o peso do império como um triste dever.

Assim não parece nada casual a escolha de Marco Aurélio como uma das grandes figuras, tanto da história como da literatura, que abre o álbum muriliano: o problema posto pelo possível sentido da falta de unidade que parecia preocupar o poeta é respondido pela citação do livro do imperador que, em 179, já compusera seu livro sob as mesmas bases. Murilo se dispunha a fazer algo muito próximo ao que fizera Marco Aurélio: esse primeiro retrato funciona também como um prefácio ao novo livro.

$\mathrm{O}$ retrato inspirado na figura de Cecco Angiolieri, "poeta cômico realista italiano do século XIII" (Mendes, 1994, p. 1.201), é apresentado como resultante das consultas bibliográficas de Murilo a uma série de textos críticos que foram atualizando, no decorrer dos anos, a interpretação da sua figura e da sua obra. Cita uma "biografia" lida que se parece com as obras de referência que consultamos nos primeiros passos de um estudo, acrescentando em seguida outras, de caráter analítico, como as de Pirandello e Gianfranco Contini, sofisticado crítico italiano. Essa mistura de tipos diversos de obras consultadas une o leitor curioso ao leitor erudito, e são essas duas figuras que, amalgamadas, dão tom à voz que compõe esses retratos. São elas que compõem, se assim pudermos dizer, o narrador dessas pequenas narrativas ou eu-poético dessa prosa poética.

Mas Cecco Angiolieri sobretudo dá a Murilo Mendes a oportunidade de discutir a função do humor na poesia, sintetizada na expressão que encontra para definir o poeta 


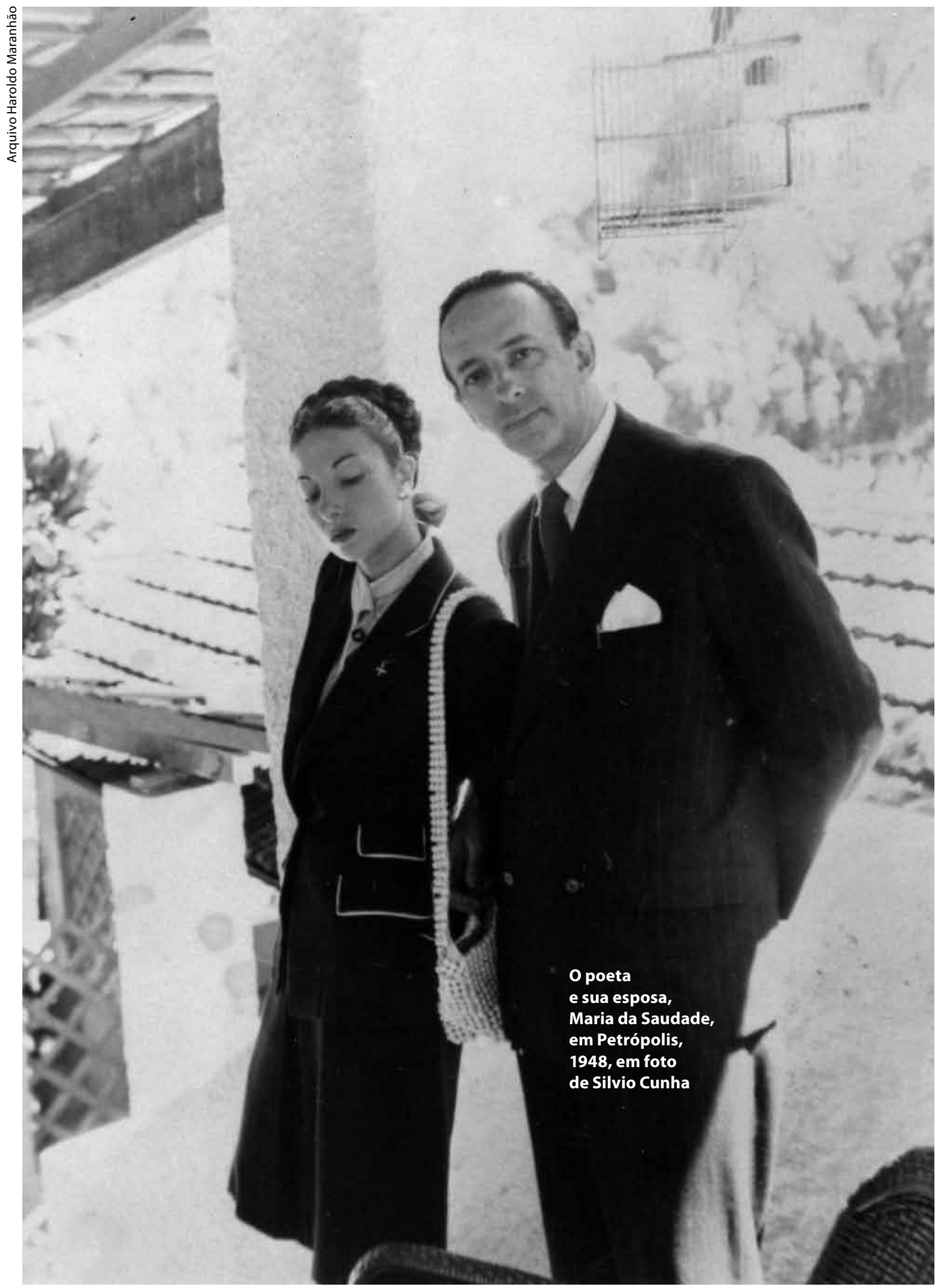


ça [...]" (Mendes, 1994, p. 1.198).

10 Continua:"[...]Quando vi a primeira vez este monumento eques tre ímpar decidi reler os pensamentos da quele que visto do Brasil parecia-me um tanto rebarbativo. Descobri então re lações de afinidade entre a estátua e o livro do imperador, cujo título na versão italiana que estudei é Colloqui con se Stesso. [...]" (Mendes, 1994, p. 1.198).

11 "[...] Cecco foi um 'despoetizador' da matéria poética, fundada no seu caso, sobre dadosconcretos, triviais Quanto a sua amada, o poeta descreve- a sob as espécies duma mulher imediata, terra-a-terra: antípoda de Beatriz. Achamo-nos muito distantes do amor cortese, suas alegorias e seus arabescos. A palavra malinconia que responta de vez em quando ao longo dos sonetos, constituiu para a crítica um cavalo de batalha: segundo alguns esta palavra 'nobre', poetizada também para semprenuma gravura de Albretch Dürer e nalguns quadros do primeiro De Chirico significaria para o nosso autor: chateação, antipatia pelo pai ou falta de dinheiro, devendo ser despojada de qualquer implicação metafísica. Segundo Gianfranco Contini, a esse malinconia convém aplicar o sentidoetimológico e clínico de umor nero [...]" (Mendes, 1994, p. 1.202

12 I Libri Degli Altri é o título dolivroquereúne a correspondência do escritor italiano Italo Calvino no seu pape de editor (cf. Calvino 1991). como um "despoetizador da matéria poética" ${ }^{\prime \prime}$. Anteriormente comparado a Villon, o Angiolieri que parece entusiasmar Murilo Mendes é o que renasce das interpretações de Gianfranco Contini, que o aproxima do realismo dantesco. Humor e realismo: não se trata em termos literários de uma questão qualquer, como sabemos, e talvez essa importância cresça se considerarmos que seus poemas-piada exigiram do poeta muita explicação, no Brasil e na Itália: estaria Murilo perguntando, em companhia desses nomes citados, qual a função do humor numa nova poética?

O poeta Dino Campana será outro retratado. A consulta aos manuais informa a Murilo que ele nasceu em 1885 e que "é a figura principal do tardio simbolismo italiano". Mais uma vez Murilo aciona seu "narrador" nas vestes de leitor, estudioso e crítico, e nos diz:

“[...] É certo que teve a intuição do 'fragmento' como saída para o impasse da poesia. Mas então os críticos subestimavam a ideia do fragmento, que mais tarde seria praticado por Ungaretti e por outros.

[...] Emilio Cecchi, depois de o conhecer pessoalmente, escreveu que perto de Campana sentia-se a poesia como se fosse uma descarga elétrica, um alto explosivo. Segundo Eugênio Montale ele criou uma poesia órfica que não se limita ao título do seu livro. Luciano Anceschi diz que Campana é talvez uma das testemunhas capitais da poesia do século na Itália, testemunha antes incômoda para uma crítica atenta aos esquemas previstos" (Mendes, 1994, pp. 1.214-5).

A "intuição do fragmento" como saída para o impasse da poesia é, ao mesmo tempo, constatação crítica e comentário sobre aqueles pequenos textos, sem aparente ligação entre eles, a não ser o itinerário poético-existencial que essa especial autobiografia é capaz de traçar. Ao falar dos poemas órficos de Campana, fala de seus próprios retratos.

Aos poucos, à medida que o livro avança, torna-se evidente que os grandes críticos literários italianos são a própria matéria da prosa e que trazem sob seus nomes as leituras e interpretações que os tornaram conhecidos, tudo amalgamado como parte integrante desses retratos: Emilio Cecchi, Eugenio Montale, Luciano Anceschi, Oreste Macrì, Natalino Sapegno, além do já citado Gianfranco Contini são nomes que, para Murilo, valem pelo que leram e comentaram, e são eleitos personagens nesse novo livro - sem que ganhem, eles próprios, retratos individuais. São parte constitutiva do novo tecido de que são feitos os retratos, e também parte da nova roupagem encontrada para o gênero memória, atravessada pela constante presença da ideia de biblioteca, bibliografia e bibliofilia.

Parte do projeto dos retratos murilianos poderia ter um sentido - borgiano - próximo àquele dado por Alberto Manguel à escritura de suas memórias. Manguel, um grande leitor, disse certa vez que se escrevesse uma autobiografia gostaria que fosse baseada exclusivamente nos livros que tiveram importância para a sua vida. Os retratos-relâmpago de Murilo são obra de outro grande leitor.

Entretanto, nesse livro, Murilo, além de fazer convergir autobiografia e projeto literário, se propõe a falar "dos livros dos outros"12 e se faz crítico da própria obra, sugerindo modos pelos quais gostaria de ser lido.

Será no retrato Jorge Luís Borges - o que não é nenhuma surpresa - que poderemos entrever Murilo, que nos fala sobre seu modo de compor em Retratos-Relâmpago:

“[...] Alguns críticos consideram-no [Borges] um simples transcritor inteligente de textos, um arquiteto de artifícios, o mestre do collage literário: ignoram que esses textos incorporam-se ao domínio pessoal de Borges apesar das armadilhas da sua erudição; e que os artifícios de Borges afinal resultam mais naturais do que o natural para um homem comum.

Para Borges a realidade é um fenômeno resultante da memória; outra alternativa: a memória seria a estrutura da própria realidade. A memória dos textos lidos, assimilados e transformados por Borges produz textos de Borges que morrerão com a morte do mundo, esvaziado de Borges" [...] (Mendes, 1994, p. 1.220). 
Nessas linhas desvela-se com facilidade o Murilo estudioso, o professor, o comentarista, o crítico que faz da leitura de outras selecionadas obras o meio para refletir sobre a sua própria produção. $\mathrm{O}$ que se destaca, enfim, na ausência de termo melhor, são os retratos como forma particular do ensaísmo de Murilo Mendes, entendido aqui como um não gênero, abarcando tanto a crítica como a poesia ou a prosa. São retratos não só as séries intituladas Retratos-Relâmpago como toda a produção das décadas de 60 e 70: suas memórias excepcionais, publicadas no livro Idade do Serrote; as descrições que faz de bichos e coisas em Poliedro.

As primeiras pistas para o Murilo ensaísta foram encontradas em Antonio Candido, ele também grande ensaísta e precocemente autodeterminado ao memorialismo. $\mathrm{O}$ ponto de partida pode ser vislumbrado no conhecido ensaio "A Vida ao Rés-do-chão", no qual a crônica praticada por seus maiores representantes - Fernando Sabino, Paulo Mendes Campos, Carlos Drummond e Rubem Braga - é estudada como gênero "menor". Diz o crítico a esse respeito:

"Por meio dos assuntos, da composição solta, do ar de coisa sem necessidade que costuma assumir, ela se ajusta à sensibilidade de todo dia. Principalmente porque elabora uma linguagem que fala de perto ao nosso modo de ser mais natural. Na sua despretensão, humaniza; e esta humanização lhe permite, como compensação sorrateira, recuperar com a outra mão certa profundidade de significado e certo acabamento de forma, que de repente podem fazer dela uma inesperada embora discreta candidata à perfeição" (Candido, 1993, p. 23).

Em 1984, a atenção para com o ensaísmo reaparece ao comentar e analisar a prosaverso - as crônicas, justamente - de Carlos Drummond de Andrade:

"Assim, mesmo em escritos rotulados de 'crônica', muitos perdem o tom dominante da gratuidade ocasional (que costumamos associar ao gênero) e vão caminhando para outra coisa: poema, estudo, autobiografia - ou um certo tipo de reflexão, em geral bem disfarçada, que deixa para trás o pretexto imediato e mostra uma dimensão imprevista. Esta última modalidade leva a pensar que ele pratica a seu modo aquilo que Montaigne chamava ensaio, ou seja, o exercício em profundidade do pensamento, a partir de estímulos aparentemente fúteis ou desligados do que acaba sendo a matéria central.É em Montaigne que penso quando vejo Drummond, numa prosa que se apresenta como algo irrelevante, deslizar do papo para reflexão de um alcance e densidade que nos fazem incluí-lo na família mental dos que 'ensaiam' o pensamento, a pretexto de motivos inesperados [...]" (Candido, 1993, pp. 17-8).

Embora não inclua Murilo Mendes entre os cronistas mineiros citados, sem dúvida se pode afirmar que há "nele um certo ar de família em relação a outros escritores do mesmo tempo e província". O próprio Antonio Candido (1987, pp. 51-69), aliás, em outra ocasião, incluiu-o no grupo, destacando a vertente memorialística e autobiográfica comum em suas literaturas.

Pode-se afirmar que Murilo Mendes, na sua produção tardia, movendo-se cada vez mais para além da fronteira entre a poesia e a prosa, procurou fazer com que o retrato fosse capaz de realizar o que Alfonso Berardinelli definiu como característico da crítica como ensaísmo, isto é, dar "voz às nossas discussões públicas, às nossas dúvidas e até mesmo às nossas conversas privadas. [A crítica ensaística] é ao mesmo tempo discussão e conversa por escrito" (Berardinelli, 2000, p. 10, tradução minha).

Partindo desses pressupostos, é possível aventar uma hipótese preliminar: é como se o que Berardinelli encontra disseminado entre os escritores da modernidade italiana, como Pasolini, Calvino, Montale, que ao escreverem sobre suas próprias obras nos indicam modos de lê-las - e também o que observa Candido a respeito da prosa de Drummond -, pudesse ser identificado em Murilo Mendes, em outra chave: comentá- 


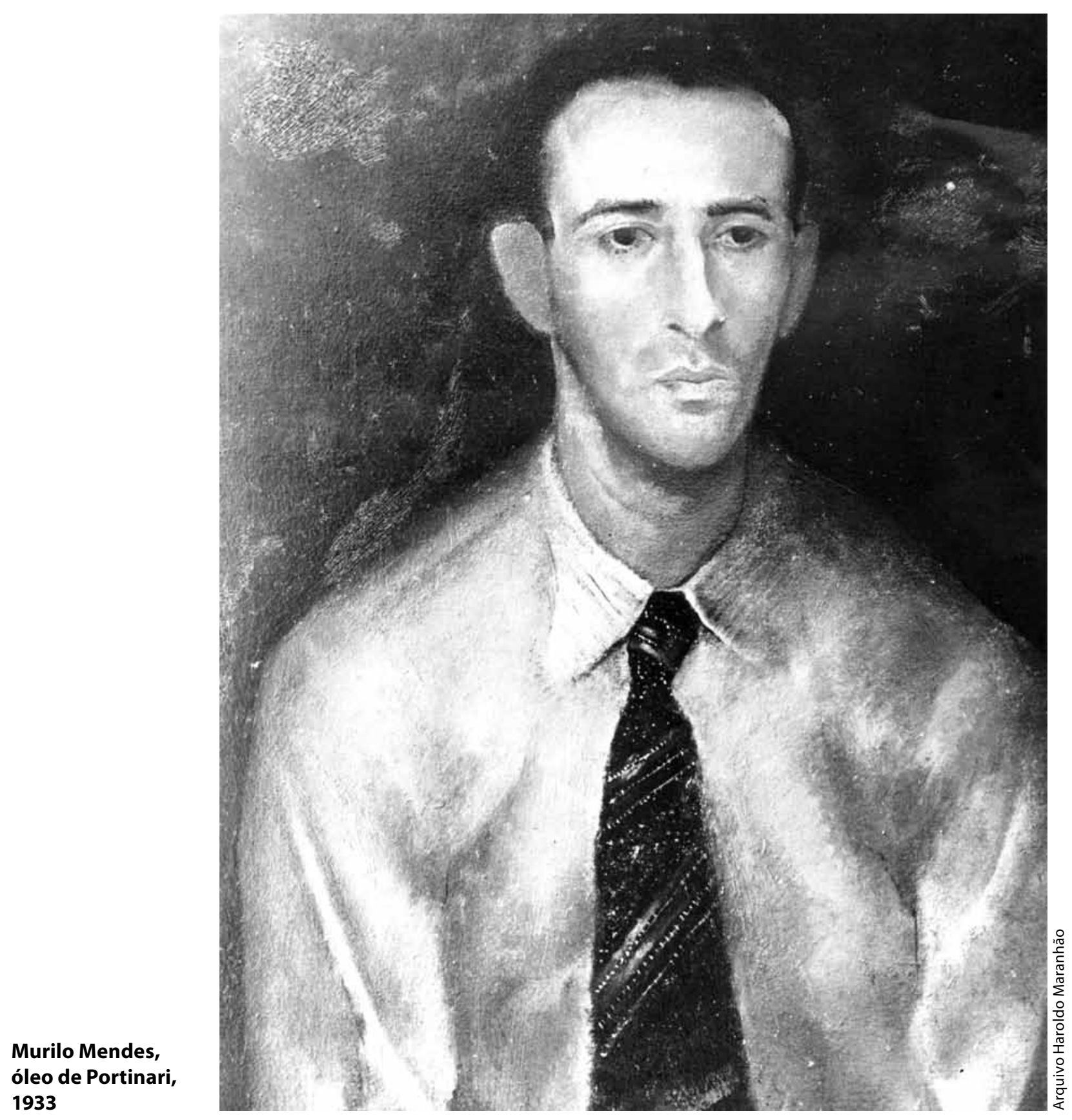

rios críticos são dispostos em tom poético, associando a matéria crítica - sobre artes e artistas plásticos, sobre escritores e obras - à matéria da poesia. Ao lado disso, os retratos de Murilo Mendes são também depoimento, memorialismo, nos quais a vida é projetada sobre as ruínas que se acumularam. Mesmo a crítica de arte, presente nos textos escritos em geral para catálogos de mostras (Mendes, 2001), pode ser compreendida a partir desse ângulo, isto é, mantém sempre traços ensa- ísticos e extrema proximidade com o retrato.

Que essa fosse a forma de diálogo público encontrado por Murilo Mendes para dar continuidade a sua obra, por longo período identificada com os projetos estéticos da lírica moderna, principalmente aquela escrita no "exílio", é o que cabe averiguar melhor. Os retratos murilianos revivem também Sainte-Beuve e seus retratos, frisam as marcas francesas da cultura muriliana (e dos intelectuais e artistas mineiros do primeiro 
Novecento, "classicizante") e são, concomitantemente, despedida e comemoração.

O feliz conceito utilizado de obra tardia, do crítico Edward Said, serviu como inspiração a este pequeno e ainda inicial artigo:

"Há anos venho estudando o fenômeno do estilo tardio, pois tem a ver com o modo como os escritores enfrentam a mortalidade em suas últimas obras e como surge um consequente estilo tardio (late style, Apätstil, style tardif) [...]. De acordo com Theodor Adorno, que é uma espécie de sumo sacerdote da melancolia do estilo tardio - ele se refere às obras-primas do terceiro período de Beethoven - as produções tardias são catástrofes" (Said, 2003, p. 287).

Aqui se procurou estender as palavras de Said para a produção do último Murilo Mendes e, a partir daí, procurou-se compreender, num relance, os retratos-relâmpago como obra tardia, na qual o "exílio" e a proximidade da morte definem novas soluções formais que são tão novas e inesperadas quanto aquelas que apresentaram o poeta ao mundo, nos anos 30 , mas trazem as marcas, mesmo que disfarçadas, da melancolia.

\section{BIBLIOGRAFIA}

AMOROSO, Maria Betânia. Murilo Mendes: O "Poeta Brasileiro" de Roma. V. I: História de uma Leitura (Introdução) e V. II: História de uma Leitura (Apêndice). Inéditos.

BERARDINELLI, Alfonso. La Forma del Saggio. Definizione e Attualità di un Genere Letterario. Venezia, Marsílio, 2000.

CALVINO, Italo. I Libri Degli Altri. Lettere 1947-1981. A cura di Giovanni Tesio.Torino,

Einaudi, 1991.

CANDIDO, Antonio. Recortes. São Paulo, Companhia das Letras, 1993. "Poesia e Ficção na Autobiografia", in A Educação pela Noite e Outros Ensaios.

São Paulo, Ática, 1987.

LIMA, Luiz Costa. “O Pai e o Trickster - Indivíduo e Cultura nos Campos Metropolitano e Marginal", in Terra Ignota. A Construção de Os Sertões. Rio de Janeiro, Civilização Brasileira, 1997.

LEONIL, Martinez. "Murilo Mendes e o Poema em Prosa", in Poéticas do Olhar e Outras Leituras de Poesia. Org. Célia Pedrosa e M. Lúcia de Barros Camargo. Rio de Janeiro, 7 Letras, 2006, pp. 67-74.

MENDES, Murilo. L'Occhio del Poeta. A cura di Luciana Stegagno-Picchio. Roma, Gangemi Editore, 2001a.

. "Vivo em Roma", in Remate de Males, n. 21, Campinas, Unicamp, 2001.

MENDES, Murilo. Poesia Completa e Prosa. Org. Luciana Stegagno-Picchio. Rio de Janeiro, Nova Aguilar, 1994.

NERHING, Marta. Murilo Mendes: Crítico de Arte: a Invenção do Finito. São Paulo, Nankin, 2003.

SAID, Edward. Reflexões sobre o Exílio e Outros Ensaios. Trad. Pedro Maia Soares.

São Paulo, Companhia das Letras, 2003. 